\title{
Pivotal role of microRNA-9 in osteosarcoma tumorigenesis and tumor progression
}

\author{
X.J. Qi, J.F. Wang, G.D. Wang, Q. Xu and H.L. Sun \\ Department of Orthopedics, Yantai Yuhuangding Hospital, Yantai, Shandong, China \\ Corresponding author: J.F. Wang \\ E-mail: jfw_king@163.com \\ Genet. Mol. Res. 15 (1): gmr.15017318 \\ Received September 14, 2015 \\ Accepted November 17, 2015 \\ Published March 24, 2016 \\ DOI http://dx.doi.org/10.4238/gmr.15017318
}

\begin{abstract}
MicroRNA-9 (miR-9) has a well-established role in various tumors; the clinical significance and potential mechanism of miR-9 in human osteosarcoma (OS) has not been elucidated. The aim of this study was to investigate the mechanism and role of miR-9 expression in osteosarcoma cells. miR-9 expression in the OS cell line MG-63 and OS tissues was compared to that in a human osteoblastic cell line (hFOB 1.19) and adjacent normal tissues, respectively, by reverse transcriptase-polymerase chain reaction. miR-9 expression was downregulated by introducing small interfering RNA against miR-9 (si-miR-9) into the cells, and the proliferative, migratory, and invasive capacities of si-miR-9-transfected MG-63 cells were compared to those of control MG-63 cells. miR-9 was significantly upregulated in OS tissues and cell lines compared to the corresponding non-cancerous bone tissues $(P<0.05)$ and human osteoblastic cell line $(P$ $<0.05)$, respectively. Upregulated miR-9 expression was also associated with increased cell proliferation $(P<0.05)$, migration $(P<0.05)$, and invasion $(P<0.05)$, and decreased apoptotic ability $(P<0.05)$. These results suggest that miR-9 may play a pivotal role in tumorigenesis and tumor progression in osteosarcoma.
\end{abstract}

Key words: MicroRNA-9; Osteosarcoma; Proliferation; Migration; Invasion; Apoptosis 


\section{INTRODUCTION}

Osteosarcoma (OS) is the most common human primary malignant bone tumor, with an incidence rate of 4-5 per million (Geller and Gorlick, 2010). OS mainly affects children and young adolescents, accounting for approximately $60 \%$ of the malignant bone tumors (Ma et al., 2009). OS mainly affects regions with active bone growth and reparation, such as the knee joint, lower femur, and upper tibia; the distal femoral and proximal tibial metaphyses are the most common sites affected by OS. Despite the rapid development in combinatorial chemotherapeutic techniques over the past decade, the 5-year survival rate of OS patients remains at $60-70 \%$, with $<50 \%$ of the patients surviving beyond 10 years (Bielack et al., 2002; Kansara and Thomas, 2007; Marulanda et al., 2008). Furthermore, the outcome of patients with metastatic OS is far worse, with a $<30 \%$ chance of survival (Ferguson and Goorin, 2001). Therefore, an in-depth understanding of the pathobiology of OS is required to develop rational options for its treatment. Despite the considerable amount of attention accorded to the highly complex molecular basis of OS over the past decade, it remains partially understood.

MicroRNA (miRNA) are small, non-coding 18-22-nucleotide RNA that could potentially regulate various cellular biological processes, including the differentiation, apoptosis, progression, and proliferation of tumor cells. Unlike small interfering RNA (siRNA), which silence the expression of a single gene, miRNA can simultaneously silence the expression of multiple genes. An average miRNA has more than 100 targets (Griffiths-Jones et al., 2008); moreover, miRNA have the potential to regulate at least $20-30 \%$ of all human genes (Lewis et al., 2005; Griffiths-Jones et al., 2008) via translational inhibition, mRNA degradation, or chromatin-based silencing. Differential miRNA expression has been described in many types of tumors (Calin and Croce, 2006; Garzon et al., 2006; Croce, 2009), which imply the involvement of miRNA in the pathogenesis of cancer, as tumor suppressors, oncogenes, or both. However, in contrast to other cancer types, little is known about the role of miRNA in the pathogenesis of OS and regulation of abnormal gene expression (Maire et al., 2011; Osaki et al., 2011).

MicroRNA-9 (miR-9) has been reported to be play an important role in several malignant cancers, such as ovarian, gastric, renal, colon, breast, esophageal, and lung cancer, and brain tumors (Guo et al., 2009; Hildebrandt et al., 2010; Shigehara et al., 2011; Zhu et al., 2012; Zheng et al., 2013; Xu et al., 2014). These studies have suggested that miR-9 may play a pivotal role in tumorigenesis and tumor progression, as well as other mechanism, in other types of cancer. The role of miR-9 in the proliferation/migration of neuronal precursors and axon extension/branching has been previously established; however, the clinical significance of miR-9 in human osteosarcoma remains to be explained. The aim of this study was to investigate the mechanism and effect of miR9 expression in osteosarcoma cells.

\section{MATERIAL AND METHODS}

\section{Ethical statement}

The study was approved by the Regional Ethics Committee of Yuhuangding Hospital. Signed informed consent forms were obtained from all patients according to the institutional regulations.

\section{Cell lines, patients, and samples}

The human osteosarcoma cell line MG-63 was obtained from the ATCC (Shanghai, 
China) and cultured in complete RPMI 1640 medium (HyClone Laboratories Inc., Logan, UT, USA) supplemented with $10 \%$ fetal bovine serum (FBS), $2 \mathrm{mM}$ glutamine, $100 \mathrm{U} / \mathrm{mL}$ penicillin, and $100 \mu \mathrm{g} / \mathrm{mL}$ streptomycin at $37^{\circ} \mathrm{C}$ in a $5 \% \mathrm{CO}_{2}$ atmosphere. The human osteoblastic cell line hFOB 1.19 was cultured in Ham's F12/Dulbecco's modified Eagle's medium (DMEM) (Gibco; Life Technologies, Carlsbad, CA, USA) supplemented with 10\% FBS, $100 \mathrm{U} / \mathrm{mL}$ penicillin, and 100 $\mu \mathrm{g} / \mathrm{mL}$ streptomycin at $33.5^{\circ} \mathrm{C}$. Tumor samples and adjacent normal tissues were obtained from 15 patients undergoing surgical resection of OS at the Yuhuangding Hospital. The samples were frozen in liquid nitrogen and stored at $-80^{\circ} \mathrm{C}$ for subsequent RNA extraction immediately after the surgery.

\section{RNA isolation and quantitative reverse transcriptase-polymerase chain reaction (qRT-PCR)}

miR-9 expression was detected by qRT-PCR. Total RNA was extracted using a commercial miRNeasy kit (Qiagen, Venlo, Netherlands) according to the manufacturer protocols. The miRNA expression levels were determined using the TaqMan miRNA RT-Real Time PCR kit (Qiagen). Single-strand cDNA was synthesized using the TaqMan MicroRNA Reverse Transcription Kit (Applied Biosystems, Foster City, CA, USA); the synthesized cDNA was amplified using the TaqMan Universal PCR Master Mix together with miRNA-specific TaqMan MGB probes. U6 snRNA was used for normalization. All samples were measured in triplicate, and the experiment was repeated at least thrice.

\section{siRNA and cell transfection}

siRNA against miR-9 (si-miR-9) and the negative control siRNA (si-NC) were synthesized by GenePharma (Shanghai, China). Cells in the exponential stage of growth $\left(1.5 \times 10^{5}\right)$ were cultured overnight on 12-well plates, and subsequently transfected with siRNA or the negative control at a final concentration of $30 \mathrm{nM}$, using the X-treme GENE transfection reagent (Ambion, Austin, TX, USA). The transfection efficiency was determined $48 \mathrm{~h}$ after the transfection by qRT-PCR.

\section{Cell proliferation assay}

The cell proliferation rate was analyzed using the Cell Counting Assay Kit-8 (CCK8) (Dojindo Molecular Technologies, Gaithersburg, MD, USA) according to the manufacturer protocols. Briefly, $5 \times 10^{3}$ cells that were starved in serum-free medium for $12 \mathrm{~h}$ were transfected with plasmids. The cells were harvested after $24,48,72$, and $96 \mathrm{~h}$. CCK-8 solution (10 $\mu \mathrm{L})$ was added to each well, the cells were incubated for $1 \mathrm{~h}$, and the absorbance at $490 \mathrm{~nm}$ was measured using an automatic multi-well spectrophotometer (Bio-Rad, Hercules, CA, USA). All experiments were conducted in triplicate.

\section{Cell apoptosis assay}

The cells were harvested, re-suspended, fixed, and re-suspended again in staining solution [1 $\mathrm{mg} / \mathrm{mL}$ RNase A, $50 \mathrm{mg} / \mathrm{mL}$ propidium iodide $(\mathrm{PI})$, and $0.1 \%$ Triton $\mathrm{X}-100$ in $\mathrm{PBS}$ ] 
$48 \mathrm{~h}$ after transfection. The stained cells $\left(1 \times 10^{5}\right.$ cells/well) were cultured on 6 -well plates until a $70-80 \%$ confluence was achieved. The apoptotic cell concentration was measured using a flow cytometric PI/Annexin V-fluorescein isothiocyanate (FITC) assay (KeyGEN Biotech. Co., Ltd., Nanjing, Jiangsu, China). At least 30,000 gated events were acquired from each sample. The results are reported as the percentage of apoptotic cells (PI and Annexin V-FITC positive) in the gated cell population. The total apoptotic rate was calculated as the early apoptotic rate plus the late apoptotic rate. The apoptosis rate of lentivirus vector-transfected cells was determined using the Annexin V-PE/7-AAD Apoptosis Detection Kit, using the same protocols. Each experiment was performed in triplicate, and the data are reported as means \pm standard deviation (SD).

\section{Transwell insert}

A 24-well Transwell insert with a pore size of $8 \mu \mathrm{m}$ (Corning, Corning, TX, USA) was used to explore the effect of miR-9 on the migration and invasion of MG-63 cells. Cells suspended in RPMI-1640 medium in the absence of FBS were added to the insert. RPMI-1640 medium $+20 \%$ FBS was added to each well in the insert. After $48 \mathrm{~h}$, the cells on the lower surface of the insert were fixed with $95 \%$ ethanol and stained with crystal violet. The invasiveness of the cells was determined using the migration assay with an additional step: the inserts were pre-coated with 40 $\mu \mathrm{L}$ BD Matrigel (1:3; BD Biosciences, San Jose, CA, USA). Six random visual fields of each insert were subsequently observed under a microscope (40X).

\section{Statistical analysis}

Statistical analysis was performed using SPSS (v.15.0) for Windows (SPSS, Inc., Chicago, IL, USA). All data are reported as means \pm standard deviation. The data were statistically analyzed by the two-sided chi-square test (categorical variable) or the Student $t$-test (continuous variable); two-sided statistical significance was set at a $P$ value of 0.05 .

\section{RESULTS}

\section{miR-9 is over-expressed in OS tissues and cell lines}

The miR-9 expression levels in 15 OS patients were determined by qRT-PCR. miR-9 expression was significantly increased in clinical OS tissues, compared to the adjacent normal renal tissues $(P<0.05$; Figure 1A). miRNA expression was also examined (by qRT-PCR) in the OS cell line MG-63 and a normal human osteoblastic cell line hFOB 1.19; miR-9 expression was higher in the OS cell line than in hFOB 1.19 ( $\mathrm{P}<0.05$; Figure 1B).

\section{si-miR-9 significantly downregulates miR-9 expression in MG-63 cells}

The role of miR-9 in human OS cells was further investigated by transfecting miR-9-specific siRNA (si-miR-9) into MG-63 cells, using a non-specific siRNA (si-NC) as the negative control. miR9 expression was significantly downregulated in cells transfected with si-miR-9 compared to those transfected with si-NC $(\mathrm{P}<0.05$; Figure $2 \mathrm{~A})$. 

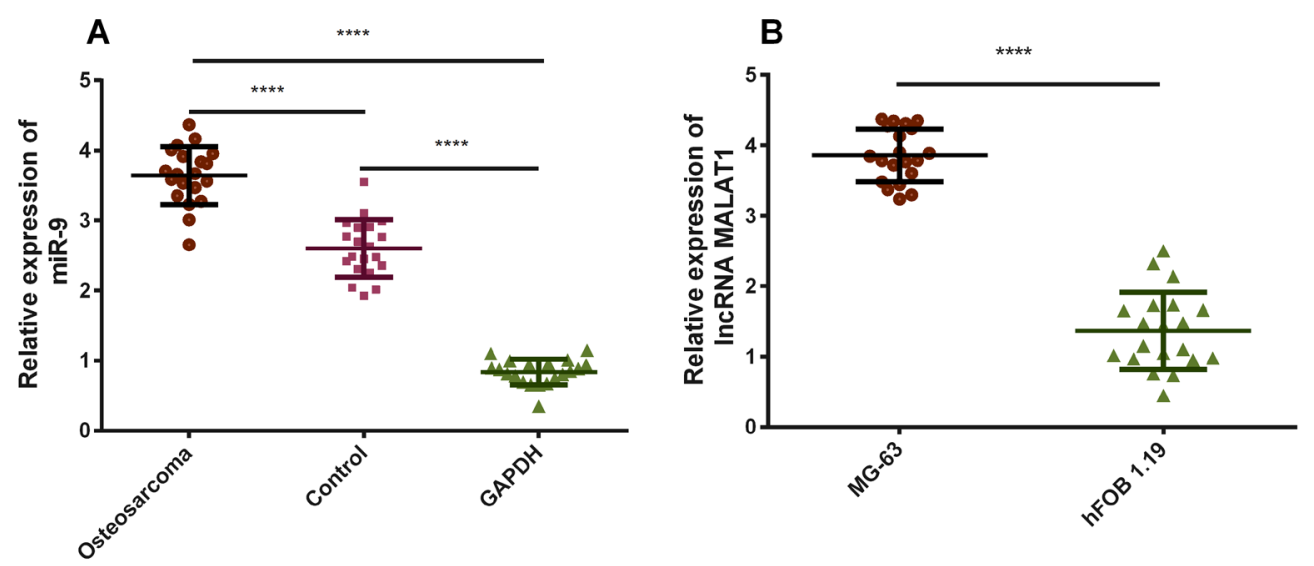

Figure 1. Expression of miR-9 in osteosarcoma tissues (A) and cell lines (B).

A

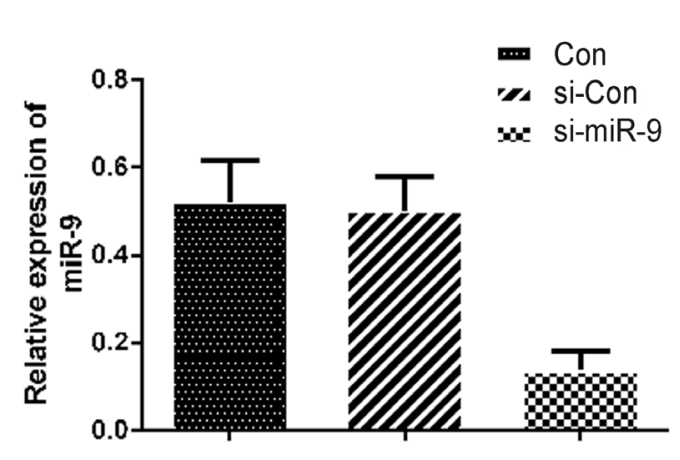

B

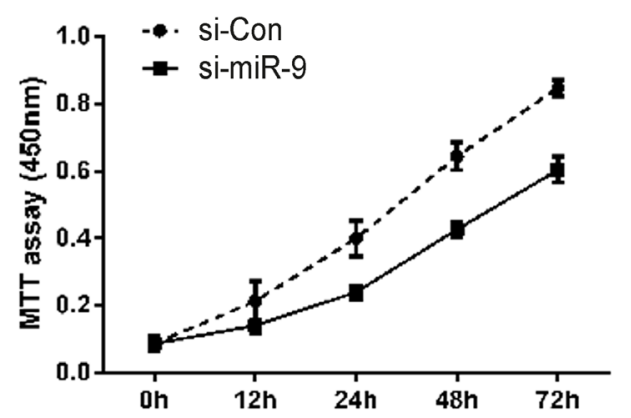

Figure 2. A. and B. Cell proliferation ability of MG-63 cells after silence of miR-9 (si-miR-9) expression.

\section{Knockdown of miR-9 inhibited cell proliferation}

The potential role of miR-9 in proliferation of OS cells was further analyzed by subjecting si-miR-9-transfected MG-63 cells to an MTT assay. The rate of proliferation of cells transfected with si-miR-9 was significantly downregulated compared to the si-NC group $(P<0.05$; Figure $2 B)$.

We then explored the potential mechanism of cell proliferation inhibition by miR-9 knockdown by flow cytometry. MG-63 cells transfected with si-miR- 9 for $48 \mathrm{~h}$ showed an increase in apoptosis, compared to those in the si-NC group $(\mathrm{P}<0.05$; Figure 3$)$.

\section{Knockdown of miR-9 inhibits cell migration and invasion}

The role of miR-9 in the regulation of cell migration and invasion in human OS cells was analyzed by wound healing and transwell invasion assays. The wound healing assay showed that the migratory rate of si-MG-63-transfected MG-63 cells was significantly lower than that of cells 
transfected with si-NC $(\mathrm{P}<0.05$; Figure 4$)$. The results of the transwell invasion assay revealed that the invasive ability of MG-63 cells transfected with si-miR-9 was notably downregulated compared to that of cells transfected with si-NC $(P<0.05$; Figure 5).
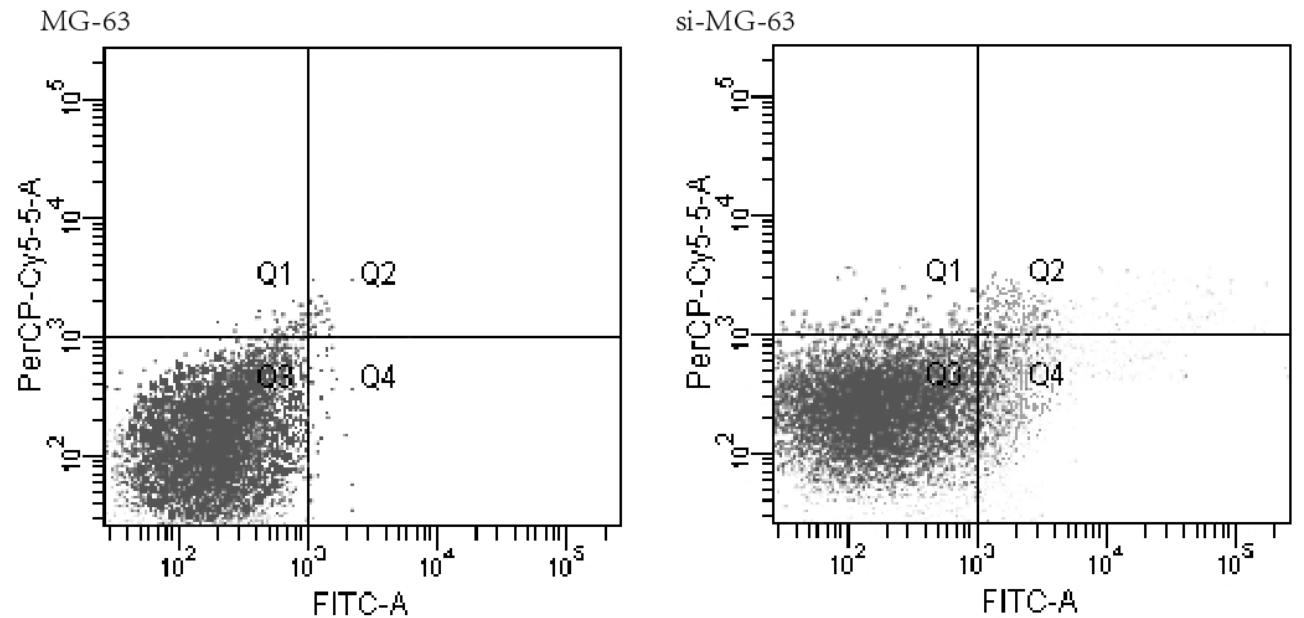

Figure 3. Cell apoptosis ability of MG-63 cells after silence of miR-9 (si-MG-63) expression.

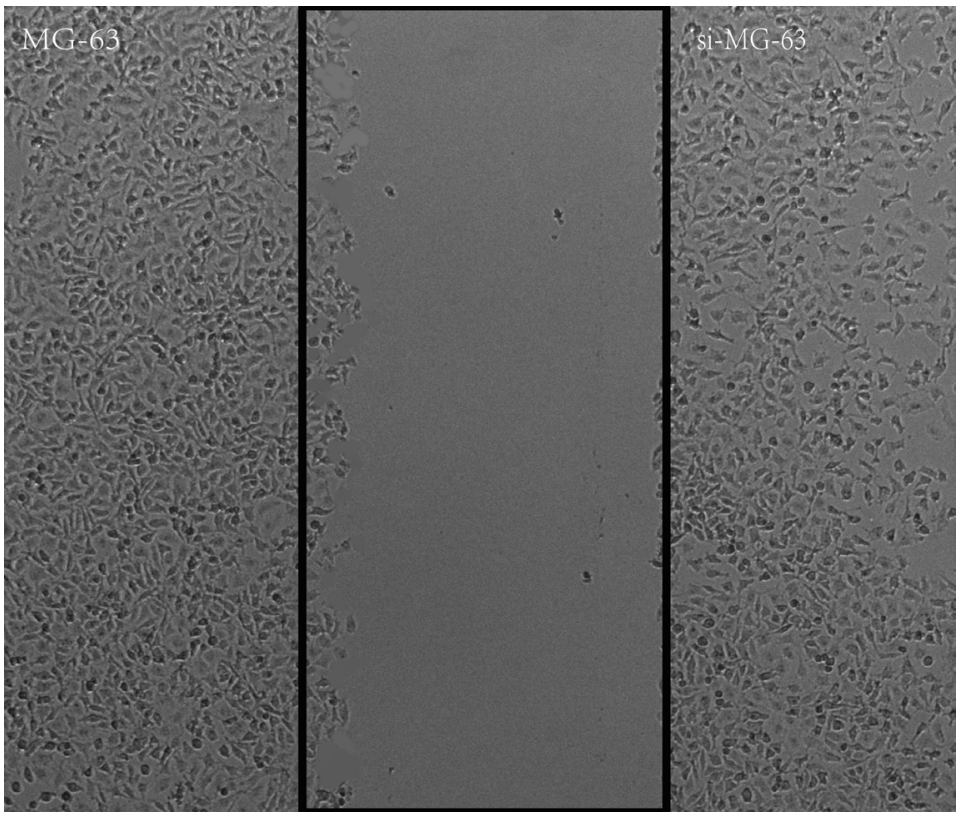

Figure 4. Cell migration ability of MG-63 cells after silence of miR-9 expression. 


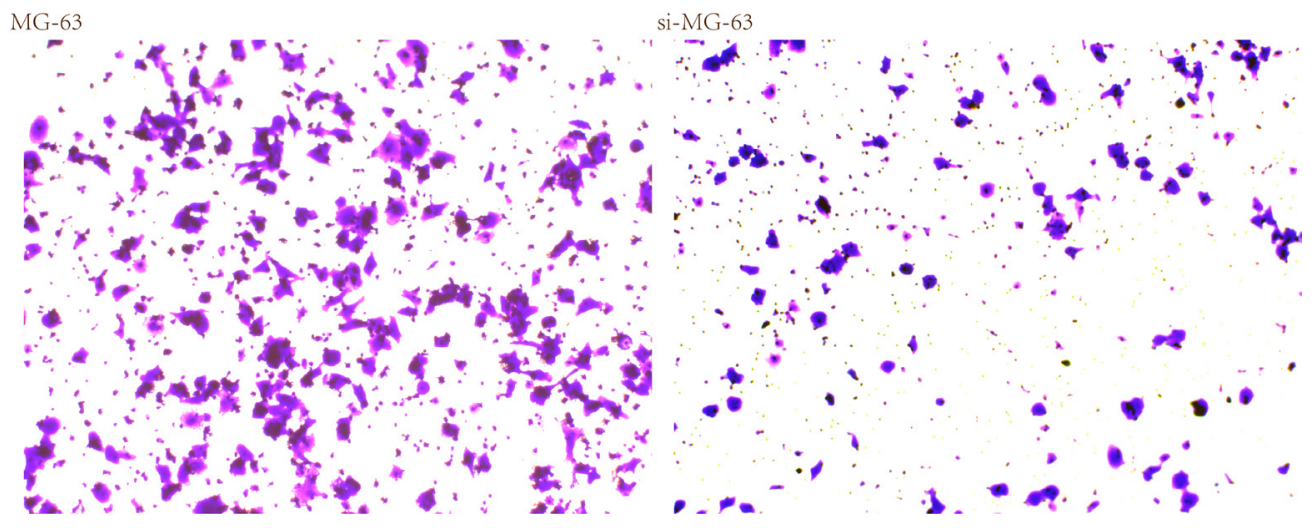

Figure 5. Cell invasion ability of MG-63 cells after silence of miR-9 expression.

\section{DISCUSSION}

Cancer gene therapy is defined as the treatment of malignant tumors through the introduction of a therapeutic tumor suppressor gene or the abrogation of an oncogene. Therefore, the discovery of miRNA and its functions has led to the introduction of a new dimension to our existing knowledge of signaling molecules and pathways for application in the development of precise therapeutic targeting strategies. Altered miRNA expression impacts human carcinogenesis in a number of human malignancies, and is also involved in the initiation and progression of human cancer; moreover, some miRNA also function as efficient diagnostic and therapeutic tools for cancer (Calin et al., 2002, 2005; Volinia et al., 2006; Deng et al., 2008). An increasing number of studies have reported that miRNA could function as tumor suppressors or have an oncogenic role in cancer formation, based on its target gene. Tumor-suppressive miRNA generally repress growth-promoting genes, while oncogenic miRNA predominantly target growth-stimulatory genes. Therefore, miRNA may be considered as promising molecular targets for the treatment of human cancers. miRNA alterations have also been reported in osteosarcoma (Song et al., 2010; Lv et al., 2014). Recent studies have shown that miRNA function as upstream regulators of osteosarcoma growth, indicating the important role of miRNA in osteosarcoma prevention and therapeutics.

In this study, miR-9 expression was analyzed in OS tissues and cell lines, and the role of miR-9 in OS cell proliferation, apoptosis, migration, and invasion was explored. miR-9 was found to be significantly upregulated in OS tissues and cell lines compared to the corresponding noncancerous bone tissues and the normal human osteoblastic cell line, respectively. Uncontrolled cell proliferation and aggressive tumor cell metastasis are two essential steps during cancer progression; the former results in orthotopic tumor growth, while the latter promotes tumor transference to distant sites. Upregulated miR-9 expression was associated with increased cell proliferative, migratory, and invasive ability, and decreased cell apoptosis.

miR-9 precursors are encoded by three genes, miR-9-1, miR-9-2, and miR-9-3, located on different chromosomes. These paralogous transcripts give rise to a unique mature $\mathrm{miR}-9$ post-processing. miR-9 was first reported as a proinflammatory signal regulator in monocytes and neutrophils (Bazzoni et al., 2009). Further studies revealed that miR-9 is one of the most abundant miRNA expressed in the developing brain (Lagos-Quintana et al., 2002), participating in 
the proliferation and regulation of migration of neural progenitor cells (Delaloy et al., 2010). Recent studies have focused on its potential role in malignant diseases. However, miR-9 appears to play different roles in tumor progression in different types of tissues (Hildebrandt et al., 2010). Other reports have indicated that miR-9 facilitates tumor cell motility and metastasis in some types of cancer such as breast cancer, lung cancer, and hepatocellular carcinoma (Mao et al., 2012; Sun et al., 2013). However, miR-9 has been reported to function as a tumor suppressor in ovarian cancer, colon cancer, and gastric cancer (Corney and Nikitin, 2008; Guo et al., 2009). These results suggest that miR-9 may play pivotal roles in tumorigenesis and tumor progression, and also exert different effects in various types of cancer.

Dysregulation of miR-9 expression in diverse cancers causes multiple effects, including genomic alterations, aberrant transcription, miR gene methylation, and defective miR processing (Calin and Croce, 2006; Ma et al., 2010). Guo et al. (2009) reported that miR-9 inhibited ovarian cancer cell growth by regulating nuclear factor kappa B1 (NF-kB1) expression. However, Tang et al. (2013) reported that miR-9 might act through the suppression of the talin 1/FAK/Akt pathway. miR9 has also been demonstrated to improve the chemotherapeutic efficacy against ovarian cancer, as targeted inhibition of miR-9 sensitizes ovarian xenograft tumors to cisplatin and PARP inhibitor (Sun et al., 2013). miR-9 has also been shown to target $C D H-1$ mRNA, which downregulated the expression of E-cadherin, thereby increasing the nuclear translocation of $\beta$-catenin and enhancing its binding with transcription factors TCF/LEF, in order to upregulate the transcription of genes that facilitate cell proliferation and angiogenesis (Ma et al., 2010). Zheng et al. (2013) identified cyclin D1 and Ets1 as new targets of miR-9 in gastric cancer; moreover, they demonstrated that miR-9 suppressed the proliferation, invasion, and metastasis of gastric cancer cells. In this study, miR-9 was found to play an oncogenic role in osteosarcoma; however, the precise mechanism with which miR-9 influences osteosarcoma tumorigenesis and progression remains to be understood.

\section{CONCLUSION}

In conclusion, we demonstrated that miR-9 was significantly upregulated in osteosarcoma tissues and cell lines compared to corresponding non-cancerous bone tissues and a normal human osteoblastic cell line, respectively. Upregulated miR-9 expression was also associated with increased cell proliferation, migration, and invasion, and decreased cell apoptosis. These results suggest that miR-9 may play a pivotal role in the tumorigenesis and progression of osteosarcoma.

\section{Conflicts of interest}

The authors declare no conflict of interest.

\section{REFERENCES}

Bazzoni F, Rossato M, Fabbri M, Gaudiosi D, et al. (2009). Induction and regulatory function of miR-9 in human monocytes and neutrophils exposed to proinflammatory signals. Proc. Natl. Acad. Sci. USA 106: 5282-5287.http://dx.doi.org/10.1073/ pnas. 0810909106

Bielack SS, Kempf-Bielack B, Delling G, Exner GU, et al. (2002). Prognostic factors in high-grade osteosarcoma of the extremities or trunk: an analysis of 1,702 patients treated on neoadjuvant cooperative osteosarcoma study group protocols. J. Clin. Oncol. 20: 776-790.http://dx.doi.org/10.1200/JCO.20.3.776

Calin GA and Croce CM (2006). MicroRNA signatures in human cancers. Nat. Rev. Cancer 6: 857-866.http://dx.doi.org/10.1038/ $\underline{\text { nrc1997 }}$ 
Calin GA, Dumitru CD, Shimizu M, Bichi R, et al. (2002). Frequent deletions and down-regulation of micro- RNA genes miR15 and miR16 at 13q14 in chronic lymphocytic leukemia. Proc. Natl. Acad. Sci. USA 99: 15524-15529.http://dx.doi. org/10.1073/pnas.242606799

Calin GA, Ferracin M, Cimmino A, Di Leva G, et al. (2005). A MicroRNA signature associated with prognosis and progression in chronic lymphocytic leukemia. N. Engl. J. Med. 353: 1793-1801.http://dx.doi.org/10.1056/NEJMoa050995

Corney DC and Nikitin AY (2008). MicroRNA and ovarian cancer. Histol. Histopathol. 23: 1161-1169.

Croce CM (2009). Causes and consequences of microRNA dysregulation in cancer. Nat. Rev. Genet. 10: 704-714.http://dx.doi. org/10.1038/nrg2634

Delaloy C, Liu L, Lee JA, Su H, et al. (2010). MicroRNA-9 coordinates proliferation and migration of human embryonic stem cell-derived neural progenitors. Cell Stem Cell 6: 323-335.http://dx.doi.org/10.1016/j.stem.2010.02.015

Deng S, Calin GA, Croce CM, Coukos G, et al. (2008). Mechanisms of microRNA deregulation in human cancer. Cell Cycle 7: 2643-2646.http://dx.doi.org/10.4161/cc.7.17.6597

Ferguson WS and Goorin AM (2001). Current treatment of osteosarcoma. Cancer Invest. 19: 292-315.http://dx.doi.org/10.1081/ $\underline{\text { CNV-100102557 }}$

Garzon R, Fabbri M, Cimmino A, Calin GA, et al. (2006). MicroRNA expression and function in cancer. Trends Mol. Med. 12: 580-587.http://dx.doi.org/10.1016/j.molmed.2006.10.006

Geller DS and Gorlick R (2010). Osteosarcoma: a review of diagnosis, management, and treatment strategies. Clin. Adv. Hematol. Oncol. 8: 705-718.

Griffiths-Jones S, Saini HK, van Dongen S and Enright AJ (2008). miRBase: tools for microRNA genomics. Nucleic Acids Res. 36: D154-D158.http://dx.doi.org/10.1093/nar/gkm952

Guo LM, Pu Y, Han Z, Liu T, et al. (2009). MicroRNA-9 inhibits ovarian cancer cell growth through regulation of NF-kappaB1. FEBS J. 276: 5537-5546.http://dx.doi.org/10.1111/j.1742-4658.2009.07237.x

Hildebrandt MA, Gu J, Lin J, Ye Y, et al. (2010). Hsa-miR-9 methylation status is associated with cancer development and metastatic recurrence in patients with clear cell renal cell carcinoma. Oncogene 29: 5724-5728.http://dx.doi.org/10.1038/ onc. 2010.305

Kansara M and Thomas DM (2007). Molecular pathogenesis of osteosarcoma. DNA Cell Biol. 26: 1-18.http://dx.doi.org/10.1089/ dna.2006.0505

Lagos-Quintana M, Rauhut R, Yalcin A, Meyer J, et al. (2002). Identification of tissue-specific microRNAs from mouse. Curr. Biol. 12: 735-739.http://dx.doi.org/10.1016/S0960-9822(02)00809-6

Lewis BP, Burge CB and Bartel DP (2005). Conserved seed pairing, often flanked by adenosines, indicates that thousands of human genes are microRNA targets. Cell 120: 15-20.http://dx.doi.org/10.1016/j.cell.2004.12.035

Lv H, Guo J, Li S and Jiang D (2014). miR-155 inhibitor reduces the proliferation and migration in osteosarcoma MG-63 cells. Exp. Ther. Med. 8: 1575-1580.

Ma L, Young J, Prabhala H, Pan E, et al. (2010). miR-9, a MYC/MYCN-activated microRNA, regulates E-cadherin and cancer metastasis. Nat. Cell Biol. 12: 247-256.

Ma O, Cai WW, Zender L, Dayaram T, et al. (2009). MMP13, Birc2 (clAP1), and Birc3 (clAP2), amplified on chromosome 9, collaborate with p53 deficiency in mouse osteosarcoma progression. Cancer Res. 69: 2559-2567.http://dx.doi. org/10.1158/0008-5472.CAN-08-2929

Maire G, Martin JW, Yoshimoto M, Chilton-MacNeill S, et al. (2011). Analysis of miRNA-gene expression-genomic profiles reveals complex mechanisms of microRNA deregulation in osteosarcoma. Cancer Genet. 204: 138-146.http://dx.doi. org/10.1016/j.cancergen.2010.12.012

Mao W, You T, Ye B, Li X, et al. (2012). Reactive oxygen species suppress cardiac NaV1.5 expression through Foxo1. PLoS One 7: e32738.http://dx.doi.org/10.1371/journal.pone.0032738

Marulanda GA, Henderson ER, Johnson DA, Letson GD, et al. (2008). Orthopedic surgery options for the treatment of primary osteosarcoma. Cancer Contr. 15: 13-20.

Osaki M, Takeshita F, Sugimoto Y, Kosaka N, et al. (2011). MicroRNA-143 regulates human osteosarcoma metastasis by regulating matrix metalloprotease-13 expression. Mol. Ther. 19: 1123-1130.http://dx.doi.org/10.1038/mt.2011.53

Shigehara K, Yokomuro S, Ishibashi O, Mizuguchi Y, et al. (2011). Real-time PCR-based analysis of the human bile microRNAome identifies miR-9 as a potential diagnostic biomarker for biliary tract cancer. PLoS One 6: e23584.http:// dx.doi.org/10.1371/journal.pone.0023584

Song B, Wang Y, Titmus MA, Botchkina G, et al. (2010). Molecular mechanism of chemoresistance by miR-215 in osteosarcoma and colon cancer cells. Mol. Cancer 9: 96.http://dx.doi.org/10.1186/1476-4598-9-96

Sun C, Li N, Yang Z, Zhou B, et al. (2013). miR-9 regulation of BRCA1 and ovarian cancer sensitivity to cisplatin and PARP inhibition. J. Natl. Cancer Inst. 105: 1750-1758.http://dx.doi.org/10.1093/jnci/djt302

Tang H, Yao L, Tao X, Yu Y, et al. (2013). miR-9 functions as a tumor suppressor in ovarian serous carcinoma by targeting TLN1. Int. J. Mol. Med. 32: 381-388. 
Volinia S, Calin GA, Liu CG, Ambs S, et al. (2006). A microRNA expression signature of human solid tumors defines cancer gene targets. Proc. Natl. Acad. Sci. USA 103: 2257-2261.http://dx.doi.org/10.1073/pnas.0510565103

Xu T, Liu X, Han L, Shen H, et al. (2014). Up-regulation of miR-9 expression as a poor prognostic biomarker in patients with non-small cell lung cancer. Clin. Transl. Oncol. 16: 469-475.http://dx.doi.org/10.1007/s12094-013-1106-1

Zheng L, Qi T, Yang D, Qi M, et al. (2013). microRNA-9 suppresses the proliferation, invasion and metastasis of gastric cancer cells through targeting cyclin D1 and Ets1. PLoS One 8: e55719.http://dx.doi.org/10.1371/journal.pone.0055719

Zhu L, Chen H, Zhou D, Li D, et al. (2012). MicroRNA-9 up-regulation is involved in colorectal cancer metastasis via promoting cell motility. Med. Oncol. 29: 1037-1043.http://dx.doi.org/10.1007/s12032-011-9975-z 